\title{
Detection of Aminoglycoside-Acetyl Transferase Enzyme Gene (aac(6')-Ib-cr) among Ciprofloxacin Resistant Isolates from the Sudan
}

\author{
Inass A. Malik* \\ School of Medicine, Ahfad University for Women, Sudan \\ *Corresponding author
}

\begin{tabular}{|l|}
\hline K e y w o r d s \\
Ciprofloxacin, \\
Resistance, \\
Enzyme, Plasmid, \\
Enterobacteriaceae \\
\hline Article Info \\
\hline $\begin{array}{l}\text { Accepted: } \\
\text { 04 July 2019 } \\
\text { Available Online: } \\
\text { 10 August } 2019\end{array}$ \\
\hline
\end{tabular}

\section{A B S T R A C T}

The aim of this study was to determine the prevalence of $a a c\left(6^{\prime}\right)-\mathrm{Ib}$-cr gene among seventy-two urinary and wound enterobacterial pathogens that were ciprofloxacin-resistant and ESBL producers from the Sudan. All the seventy-two isolates were screened by PCR for the presence of the $a a c\left(6^{\prime}\right)$ $I b-c r$ gene. The new variant of the aminoglycoside acetyle transferase enzyme (aac(6')-Ib-cr) gene was detected among 52 of the 72 test isolates (72\%) including Escherichia coli, Klebsiella pneumoniae, Enterobacter cloacae and Salmonella spp. This finding shows that the new variant aminoglycoside-acetyl transferase gene conferring resistance to ciprofloxacin is highly prevalent (72\%) among the isolates from Sudan. This is the first study to report on the detection of aminoglycoside-acetyl transferase enzyme gene from the Sudan.

\section{Introduction}

Resistance of microorganisms to antibiotics has been developing for more than two billion years (Egorov et al., 2018). Enzymatic drug modification is one of the major mechanisms developed by some bacterial organisms to resist the effect of the antimicrobial drugs. These modifying enzymes (ß-lactamases, aminoglycoside modifying enzymes and chloramphenicol cetyltransferase) are usually specific for a single antimicrobial group such as B-lactams, aminoglycosides and chloramphenicol. Fluoroquinolones are synthetic antimicrobial drugs and have been considered safe from naturally occurring antimicrobial-modifying enzymes (Robicsek et al., 2006a). A new variant of aminoglycoside acetyl transferase enzyme (aac(6')-Ib-cr) has been discovered to confer resistance to both aminoglycosides and fluoroquinolones. Although the degree of resistance conferred is small; this mechanism was shown to act additively with anotherplasmid mediated resistance mechanism mediated by qnr genes (Hooper et al., 2016).

Plasmid-mediated quinolone resistance (PMQR) mechanisms provide only low-level of resistance that does not exceed the clinical 
breakpoint for susceptibility. Nonetheless it facilitates the selection of higher-level resistance and makes infection by pathogens containing PMQR harder to treat (Jacoby et al., 2014). Even alone the new variant enzyme-aac( $\left.6^{\prime}\right)$-Ib-cr facilitates the selection of more resistant mutants among a fluoroquinolone-exposed population of bacteria (Robicsek et al., 2006a).

AAc(6')-Ib-cr reduces the activity of ciprofloxacin and norfloxacin by Nacetylation at the amino nitrogen on its piperazinyl constituent (Park et al., 2006). However, other members of the group such as Moxifloxacin and levofloxacin, are not affected by these enzymes due to lack of the piperazinyl constituent from its structure.

The activity of the new variant enzyme $\left(a a c\left(6^{\prime}\right)-I b-c r\right)$ against the aminoglycosides (kanamycin, tobramycin and amikacin) is maintained with only slight diminution relative to the activity of $a a c\left(6^{\prime}\right)-I b$ (Robicsek et al., 2006b).

An association between quinolone resistance and the production of extended-spectrum $\beta$ lactamase (ESBL) enzymes has been reported by many studies among enterobacterial pathogens (Paterson et al., 2000). The new variant of aminoglycoside acetyl transferase enzyme (aac(6')-Ib-cr) represents a new mechanism of resistance for quinolone agents.

This is the first study to determine the prevalence of $a a c\left(6^{\prime}\right)-I b-c r$ among ciprofloxacin resistant enterobacterial pathogens from Sudan.

\section{Materials and Methods}

\section{Bacterial isolates}

The total number of bacterial isolates tested, was about three hundred and twenty four multidrug resistant (MDR) bacterial isolates. Obtained from urine and wound samples from patients who presented to the microbiology laboratories in Khartoum and Omdorman hospitals in the Sudan. Bacterial strain identification was conducted by standard microbiology methods (Forbes et al., 2007). Isolates were stored at $-20^{\circ} \mathrm{C}$ in cryopreservers.

\section{Susceptibility testing}

All bacterial isolates (324) were tested for antibiotic susceptibilities by the disc diffusion method according to BSAC standardised methods (Andrews J.M. 2004) using IsoSensitest agar (Oxoid Ltd, Basingstoke, UK). The minimum inhibitory concentration (MIC) to nalidixic acid and ciprofloxacin were determined by the Etest method (AB Biodisk, Solna, Sweden).

\section{ESBL production}

Screening for ESBL production was determined by susceptibility to Cefpodoxime and was confirmed phenotypically by the combined disc method (Carter et al., 2000). It was characterized genotypically by the detection of bla genes by PCR and nucleotide sequencing on a separate report (Malik et al., 2019a). Isolates that were found to be ESBLs producers were screened further by PCR for the presence of the $q n r$ genes (Malik et al., 2019b)

Strains of MDR Enterobacteriaceae that were quinolone-resistant and ESBL producers were screened by PCR for the presence of the $a a c\left(6^{\prime}\right)-I b-c r$ gene and gyrA mutation (Hooper et al., 2016).

\section{PCR and nucleotide sequencing}

DNA was extracted by boiling for 10 min after it was suspended in a 5\% chelex 100 Resin 
slurry (Bio-Rad Laboratories) in a sterile distilled water. PCR was performed to detect the presence of $a a c\left(6^{\prime}\right)-I b-c r$ gene (Park et al.,2006) and gyrA mutation. PCR products were detected by electrophoresis on $1 \%(\mathrm{w} / \mathrm{v})$ agarose gels. Nucleotide sequence analysis was performed using the respective PCR primers for both directions using ABI 3100 automated sequencer (Warrington, UK), nucleotide sequence structures were compared with the data base using BLAST.

\section{Results and Discussion}

Of all multidrug resistant isolates tested, seventy two were ESBL producers (Malik et al., 2019a) and were resistant to quinolones. In total 52 isolates of the 72 test isolates $(72 \%)$ were positive to $a a c\left(6^{\prime}\right)-I b-c r$ and this includes Escherchia coli, Klebsiella pneumoniae, Enterobacter cloacae and Salmonella spp. (Table 1). gyrA gene mutation was not detected among the test isolates.

All $a a c\left(6^{\prime}\right)-I b-c r$ positive isolates were resistant to kanamycin (zone of inhibition < $16 \mathrm{~mm}$ ) and were all sensitive to amikacin (zone of inhibition $>20 \mathrm{~mm}$ ). Only nine isolates were sensitive to gentamicin (zone of inhibition $>20 \mathrm{~mm})$. aac $\left(6^{\prime}\right)-\mathrm{Ib}-\mathrm{cr}$ positive isolates were multidrug resistant, they carry resistance to trimethoprim/sulphamethoxazole, tetracycline, chloramphenicol, amoxicillin and to cephalosporins.

Six (12\%) aac (6')-Ib-cr positive isolates carry plasmid-mediated ciprofloxacin resistance determinants ( $q n r$ genes) (Malik et al., 2019b) (Table 2) and were ESBL producers carrying blagenes either CTX-M and/or SHV (Malik et al., 2019a).

Development of the main resistance mechanisms is associated with the evolution of superfamilies of bacterial enzymes due to the variability of the genes encoding them
(Egorov et al., 2018). Thirty variants of the aminoglycoside acetyl transferase encoding gene were reported since 1986 . The two amino-acid (Trp102Arg and Asp179Tyr) changes responsible for the ciprofloxacin modification phenotype are unique to this variant, was first reported in 2003 and now widely disseminated (Robicsek et al., 2006a). This is the first study to report on the detection of the new variant $\left(a a c\left(6^{\prime}\right)-I b-c r\right)$ encoding a ciprofloxacin-modifying enzyme from Sudan.

All isolates from this study that tested positive by PCR for the presence of (aac( $\left.\left.6^{\prime}\right)-I b\right)$ gene, were all identified by sequencing as the aminoglycoside acetyl transferase that confers low-level ciprofloxacin resistance. High prevalence of the new variant $a a c\left(6^{\prime}\right)-I b$ gene was detected among the isolates from this study $(72 \%)$ coinciding with other reports (Robicsek et al., 2006a and Park et al., 2006) and was identified among a variety of enterobacterial isolates. The highest prevalence was among E.coli $(62 \%)$ followed by Klebsiella spp (27\%) the least was among enterobacter isolates, coinciding with other studies (Park et al., 2006., Ruiz et al., 2011., Piout et al., 2008., Kim et al., 2009 and Kim et al., 2009).

Other quinolone resistance mechanisms were tested among $a a c\left(6^{\prime}\right)-I b$ positive isolates. All isolates were negative for gyrA gene mutation and only six isolates (8\%) were found to be positive for $q n r$ gene including Klebsiella spp and Enterobacter spp (Malik et al., 2019b). The above finding shows that there is no clear association between the carriage of the new variant $a a c\left(6^{\prime}\right)-I b$ gene and the $q n r$ genes coinciding with a study from the United states of America (Park et al., 2006). Strains harbouring both plasmid mediated resistance mechanisms ( $q n r$ and $a a c\left(6^{\prime}\right)-I b-c r$ ) showed high levels of resistance to quinolones (MIC< $0.25 \mathrm{mg} / \mathrm{l}$ ) as reported by other studies (Hooper et al., 2015). 
Table.1 The bacterial species identified and tested for $a a c\left(6^{\prime}\right)-I b-c r$ gene

\begin{tabular}{|l|l|}
\hline Bacterial isolate & Number of isolates \\
\hline Escherchia coli & $32(62 \%)$ \\
\hline Klebsiella pneumoniae & $14(27 \%)$ \\
\hline Enterobacter cloacae & $4(8 \%)$ \\
\hline Salmonella spp & $2(3 \%)$ \\
\hline
\end{tabular}

Table.2 aac(6')-Ib-cr positive isolates encoding other ciprofloxacin-resistance Genes and bla genes

\begin{tabular}{|c|c|c|c|c|c|}
\hline$a a c\left(6^{\prime}\right)-I b-c r$ gene & qnr-gene & bla-gene & $\begin{array}{c}\text { gyrA- } \\
\text { gene }\end{array}$ & isolate & Source \\
\hline +ve & $q n r-\mathrm{A} 1$ & SHV5a & -ve & E.cloacae & Urine \\
\hline +ve & $q \mathrm{nr}-\mathrm{A} 1$ & CTX-M15,SHV5 & -ve & E.cloacae & Urine \\
\hline +ve & $q \mathrm{nr}-\mathrm{B} 1$ & CTX-M15,SHV11 & -ve & K.pneumoniae & Wound \\
\hline +ve & $q \mathrm{nr}-\mathrm{B} 1$ & CTX-M15,SHV5a & -ve & K.pneumoniae & Urine \\
\hline +ve & $q \mathrm{nr}-\mathrm{B} 1$ & CTX-M15,SHV11 & -ve & K.pneumoniae & Urine \\
\hline +ve & $q \mathrm{nr}-\mathrm{B} 1$ & CTX-M15,SHV5 & -ve & K.pneumoniae & Urine \\
\hline
\end{tabular}

The two resistance genes were reported to be part of an integron in a multiresistance plasmid which may contain other PMQR genes detected in the plasmid analysis and conjugation studies conducted on the same group of isolates on a separate study (Malik et al., 2019b)

Fluoroquinolone resistance at high levels has been associated with multiple mutations in the chromosomal genes for the target enzymes and/or changes in expression of efflux pumps and porins. They act by inhibiting bacterial isomerases enzymes, namely DNA gyrase and topoisomerases IV (Hooper et al., 2015).

The new variant acetyle transferase enzyme confers a low level of ciprofloxacin resistance i.e. below the break point of quiolones resistance. However all test isolates showed high resistance to ciprofloxacin, and were gyrA negative. Only $6 \%$ of these isolates were harbouring other resistance mechanisms (qnr genes) to ciprofloxacin. This suggests that, another mechanism of quinlone resistance could be involved among these isolates such as changes in expression of efflux pumps and porins led to the rise of resistance level among these isolates.

Isolates from this study were resistant to ciprofloxacin (MIC $<0.25 \mathrm{mg} / \mathrm{l}$ ), and were all kanamycin resistant but amikacin sensitive, only nine isolates were gentamicin sensitive. Acquisition of The PMQR mechanism of the new variant aminoglycoside acetyl transferase enzyme (aac(6')-Ib-cr) provides a low quinolone resistance level that facilitates the emergence of higher-level of resistance in the presence of quinolones at therapeutic levels and the selection of resistance to other antimicrobials carried by Multidrug resistant pathogens.

The over use of quinolones and aminoglycosides (kanamycin, tobramycin and amikacin) will lead to selection of resistant strains harbouring the $a a c\left(6^{\prime}\right)-I b-c r$ gene and its dissemination will reduce the efficiency of both antimicrobials. 
All isolates from this study harboring the $a a c\left(6^{\prime}\right)-I b-c r$ gene were multidrug resistant and ESBL producers encoding either CTXM15 which was reported by many studies (Paterson et al., 2000) and/or SHV bla genes (Malik et al., 2019a). Cotransmission of these resistance genes on the same plasmid will create a pan-resistant species that are hard to treat and control. And will render most of the antimicrobial groups ineffective for the treatment of infections.

\section{References}

Andrews J M. 2004. BSAC standardized disc susceptibility testing method (version 3). J Antimicrob Chemother. 53: 71328 .

Carter MW, K.J. Oakton., M. Warner and D.M. Livermore. 2000. Detection of Extended-Spectrum beta-lactamases in Klebsiellae with the Oxoid combination disk method. J Clin Microbiol 38: 4228 4232

Egorov. A.M., Ulyashova. M.M., and Rubtsova. M.Y. 2018. Bacterial enzymes and Antibiotic resistance. Acta Naturae. 10(4): 33-48.

Forbes B.A., D.F. Sahm and A.S. Weissfield. 2007. Overview of bacterial identification- Methods and strategies. Baily and Scott's Diagnostic Microbiology, $12^{\text {th }}$ edition. Mosby Elsevier).

Hooper C.D and G.A. Jacoby. 2015. Mechanisms of drug resistance: quinolone resistance. Ann N Y Acad Sci. 1354(1): 12-31.

Hooper. D.C. and G.A. Jacoby. 2016. Topoisomerase Inhibitors: Fluoroquinolone Mechanisms of Action and Resistance. Cold Spring Harb Perspect Med. 1; 6(9).

Jacoby. G.A., J. Strahilevitz and D.C. Hooper. 2014. Plasmid-mediated quinolone resistance. Microbiol Spectr. 2(2):
10.1128

Kim ES., JY. Jeong., JB. Jun., et al., 2009. Prevalence of $a a c\left(6^{\prime}\right)-I b-c r$ encoding a ciprofloxacin-modifying enzyme among Enterobacteriaceae blood isolates in Korea. Antimicrob Agents Chemother. 53: 2643-2645.

Kim HB, CH. Park, CJ. Kim., EC. Kim., GA. Jacoby and DC. Hooper. 2009. Prevalence of plasmid-mediated quinolone resistance determinants over a 9-year period. Antimicrob Agents Chemother. 53(2): 639-645

Malik I.A., K.M. Elhag. 2019b. The first determination of the Plasmid-mediated Quinolone resistance determinants qnrA and qnrB from the Sudan. Int.J.Curr.Microbiol.App.Sci. 8(03):1612-1618.

Malik. I.A and K.M. Elhag. 2019a. Charecterisation of Extended spectrum $\beta$-Lactamases among Multidrug resistant Enterobactericeae from Sudan. J Pure Appl Microbol. 13(1): 61-68.

Park, C. H., A. Robicsek, G. A. Jacoby, D. Sahm and D. C. Hooper 2006. "Prevalence in the United States of $a a c\left(6^{\prime}\right)-I b-c r$ encoding a ciprofloxacinmodifying enzyme. Antimicrob Agents Chemother. 50(11): 3953-5.

Paterson DL, L. Mulazimoglu., J.M. Casellas et al., 2000. Epidemiology of ciprofloxacin resistance and its relationship to extended-spectrum betalactamase production in Klebsiella pneumoniae isolates causing bacteraemia. Clin Infect Dis 30: 473-8)

Pitout J.D., Y. Wei., DL. Church and DB. Gregson. 2008. Surveillance for plasmid-mediated quinolone resistance determinants in Enterobacteriaceae within the Calgary Health Region. Canada: the emergence of $a a c\left(6^{\prime}\right)-I b-c r$. J Antimicrob Chemother. 61: 999-1002.

Robicsek, A., G. A. Jacoby and D. C. Hooper. 2006b. The worldwide emergence of 
plasmid-mediated quinolone resistance. Lancet Infect Dis 6(10): 629-40.

Robicsek, A., J. Strahilevitz, G. A. Jacoby, M. Macielag, D. Abbanat, C. H. Park, K. Bush and D. C. Hooper. 2006a. Fluoroquinolone-modifying enzyme: a new adaptation of a common aminoglycoside acetyltransferase. Nat
Med 12(1): 83-8.

Ruiz E., A Rezusta, Y Saenz., et al., 2011. New genetic environments of aac (6')Ib-cr gene in a multiresistant Klebsiella oxytoca strain causing an outbreak in a pediatric intensive care unit. Diagn Microbiol Infect Dis. 69: 236-238

\section{How to cite this article:}

Inass A. Malik. 2019. Detection of Aminoglycoside-Acetyl Transferase Enzyme Gene (aac $\left(6^{\prime}\right)$ Ib-cr) among Ciprofloxacin Resistant Isolates from the Sudan. Int.J.Curr.Microbiol.App.Sci. 8(08): 230-235. doi: https://doi.org/10.20546/ijcmas.2019.808.027 